\title{
A Sea of Riches: Teaching an Interdisciplinary Environmental Justice Course through Political Theory On-Campus and Online
}

Teena Gabrielson, University of Wyoming

Kaitlyn Watts, Helena High School, Helena, Montana

ABSTRACT This article reflects on two specific sets of questions-both of which were prominent in conversations regarding the future of teaching in higher education-that emerged as we developed a pedagogy designed to advance the primary substantive goals of environmental justice. The first set of questions asks how to enhance interdisciplinary thinking and communication in a single course; the second asks how best to teach critical thinking online. We identify key challenges in both areas in a discussion of our experience in teaching two contemporaneous venues-one on-campus and one online-of an environmental justice course grounded in the subfield of political theory.

I $\mathrm{n}$ the past three decades, the concept of environmental justice has evolved from a narrow focus on inequalities in environmental risk with disproportionate burdens for low-income neighborhoods and communities of color, to a much broader engagement with various socioecological issues-from food to climate justice-and a deeper and more nuanced conceptualization of the social, political, economic, cultural, and environmental preconditions for justice (Schlosberg 2013). Accompanying this growth in the field is an expansion in the disciplinary "homes" of environmental justice courses. Whereas these courses once were principally offered by the disciplines of sociology, geography, natural resources, and urban planning, today they also populate the curricula of American studies, public health, environmental studies, and political science. Spanning these disciplines, issues of environmental justice are inherently interdisciplinary. Yet, many of the core concepts on which the field restsincluding the understanding of justice, rights, and inequality-are studied primarily by political theorists.

We appreciate both the interdisciplinary character of the field and the particular resources that political theory offers for its study. In this article, we describe our effort to align the primary substantive concerns of environmental justice with a parallel pedagogy that informs the construction and teaching of the course at the University of Wyoming. We focus on two objectives that are increasingly

Teena Gabrielson is an associate professor in the department of political science at the University of Wyoming. She can be reached at tgabriel@uwyo.edu.

Kaitlyn Watts is a teacher of government and world history at Helena High School in

Helena, Montana. She can be reached at_kwatts@helena.k12.mt.us. relevant to higher education: (1) how to advance interdisciplinary understanding and communication while still maintaining a curricular need for disciplinary depth in a single course; and (2) how best to teach the content and skills of political theory online. In both cases, there are substantial bodies of literature regarding the more traditional aims of pursuing interdisciplinary thinking through curricula (rather than single courses) and critical thinking in oncampus courses. This article explains how we drew on these and other sources to develop a course that makes upper-division political theory accessible to online students, expands their resources for thinking about the complex issue of environmental justice, and provides an opportunity for them to apply these insights to their own disciplinary thinking. ${ }^{1}$

\section{ENROLLMENT, COURSE STRUCTURE, AND INTERDISCIPLINARITY}

Our course was designed to meet three objectives. First, we sought to introduce students to various theories of justice and to explain key aspects of the development of both scholarly and activist conceptions of environmental justice. Second, we aimed to cultivate students' critical thinking regarding "the environment," the creation and maintenance of social inequalities, and the synthesis of environmentalism and social justice. Third, we strove to build a common conceptual ground wherein robust interdisciplinary exchange could occur. To achieve these objectives, we based the course on the discipline of political theory, adopted a "pedagogy of connection" to cultivate interdisciplinary exchange (Di Chiro 2006; Dillon 2006, 2008), and offered the course online as well as on-campus to increase student access to both environmental justice and political theory. 
Regarding the first of these objectives, we argue that a theoretical foundation is essential to developing students' understanding of concrete cases of environmental injustice. Therefore, we dedicated the first third of the semester to building a common language and theoretical foundation through the study of several theories of justice (i.e., utilitarian, distributive, recognition, capability, and responsibility). To this we added concepts including intersectionality, performativity, and racialization - particularly in their imbrication with conceptions of "nature" and "the natural"-for the insights they offer into structural aspects of environmental injustice. The second third of the semester progressed from theory to practice as we focused on the domestic history of the environmental justice movement; implementation of the concept in the US regulatory structure; methodological works on risk assessment; and case studies involving questions of gender, scale, and the unique experience of Native American communities. This section of the course demonstrated the inherent interdisciplinarity of problems of environmental justice by illustrating how related questions impinge on environmental remediation, community organization and activism, geographic questions of scale, global chains of production and consumption, public health policy, and risk analysis-to name only a few. At this time, students also began research on their final paper, an environmental justice case study. The final third of the semester focused on environmental justice in global and transnational contexts as well as the writing and presentation of the case studies. ${ }^{2}$ tools are used for making connections" (Latuca et al. 2004). In our course, the topic of environmental justice provided the framework and specific concepts such as "scale" and exercises such as Brief Class Assignments (BCAs) served as tools to develop interdisciplinary thinking and communication. For the BCAs, each student wrote five one-page, single-spaced reflective essays on an assigned open-ended question related to the readings (e.g., "What is the environment?"). Students were encouraged to think deeply and to give careful attention to essay organization and writing mechanics. They were then divided into learning groups in which they met (i.e., during class on-campus and in discussion threads online) to peer review and discuss their papers, after which the class as a whole took up the topic.

This assignment served two purposes: (1) it created the opportunity for meaningful interdisciplinary exchange through repeated interaction; and (2) given the politically sensitive nature of issues of environmental injustice, it provided time and space for students to reflect on and share their personal thoughts. As Auerback advised, "A class on human differences need [s] to engage students on a very personal level" (2012, 516). Furthermore, we hoped the exercises might work to "make environmental justice 'real' for students who do not necessarily come from a daily lived reality of environmental injustice" and to encourage reflection "on how privilege and power operate in complex ways in contemporary society" (Sze 2006, 125).4

\section{This assignment served two purposes: (1) it created the opportunity for meaningful interdisciplinary exchange through repeated interaction; and (2) given the politically sensitive nature of issues of environmental injustice, it provided time and space for students to reflect on and share their personal thoughts.}

Given the interdisciplinarity of environmental justice problems, we sought to attract students from a variety of fields to take the course. We cross-listed it with the environment and natural resources program, advertised it broadly, and offered it online. In the on-campus venue, roughly half of the students came from political science; the remainder represented American studies, global and area studies, geography, rangeland ecology, botany, energy resource management, wildlife and fisheries, and business management. In the online venue, political science majors initially comprised only one third of the students, with the remainder majoring in sociology, economics, energy resource management, elementary education, psychology, biology, and anthropology. ${ }^{3}$ During the first few weeks of the course, there was a decline in the diversity of academic fields represented. Of those who completed the course, in both venues, political science majors comprised half of the students. Given some of the students' reasons for dropping the course we suspect that although the structure of the course had clear advantages, the initial focus on theory contributed to the decrease in nonmajors. Despite this problem, we were satisfied with the success of the assignments in cultivating interdisciplinary exchange.

We approached the teaching of interdisciplinarity through a "pedagogy of connection" (Dillon 2008) that aims to provide a "framework and tools to conceptualize and facilitate integrative work. The framework focuses on the contexts of connection; the
Overall, students initially struggled with the genre of carefully crafted personal reflection but, in time, they came to appreciate the assignment. Despite the demographics of the university, together, the venues included a diversity of students including individuals who self-identified as Latino, Native American, African American, and Tibetan. Many students shared experiences of injustice and misrecognition related to religious affiliation, gender, and class, either at home or abroad. It is difficult to pinpoint the source of this openness (which at times created discomfort); however, given the students' comments, we think the BCAs were integral in creating an atmosphere that was conducive to extensive and probing discussion. Many students demonstrated increased depth and sophistication in their thinking and improvement in their writing skills throughout the semester. Through multiple iterations of the BCA exercise, we also witnessed a proliferation in connections that students made across disciplines. In their evaluations, several students commented on how much they learned from their peers through discussion and the BCA exercises. Their papers and responses suggest that the BCAs provided a means of interdisciplinary learning, whereby students connected new information to their existing disciplinary knowledge base (Latuca et al. 2004).

Although we hesitate to weigh too heavily the evidence from one iteration of the course, in future semesters, we intend to not only keep the BCAs but also to augment them with additional 
opportunities for interdisciplinary exchange by incorporating teamwork in the exercises. We also intend to develop on-campus workshops and online modules that draw on staff expertise to focus on specific skills appropriate to the development of the research paper, such as the close reading of texts, mapping of distributional environmental inequalities (potentially through GIS technologies), and oral presentations (or online, student-produced movies). Finally, rather than using the "foundation and extension" model for structuring the course readings, the next iteration will retain but also incorporate the theoretical material throughout the entire semester; this will avoid intimidating nonpolitical science students at the outset.

\section{TEACHING POLITICAL THEORY ONLINE}

There is little doubt that online courses have moved from the margin to the center in the thinking of most American higher education institutions; a corresponding leap in online pedagogy is also underway. In keeping with two aims central to the environmental justice movement-that is, thinking critically about "the environment" and including as many voices and experiences as possible in those conversations-we sought to enhance the social as well as the intellectual diversity of students by teaching one section of our course online. The University of Wyoming is the only fouryear postsecondary institution in the state, with only one full-time faculty teaching political theory. Therefore, if rigorous politicaltheory courses are not available online, many students-especially on-campus classroom exercises in the online community. All students, regardless of which venue, were required to participate in discussions and to complete five BCAs, two "take-home" exams, a final research paper, and an "oral" presentation. In this way, we sought to make our instructional strategies and course assignments in the two venues mirror one another. In retrospect, this was a mistake. We now agree that the objectives for both venues should be the same but that the instructional strategies should differ depending on the particular resources and constraints of each format. In the following discussion, we offer illustrative examples.

Student participation is critical to the teaching of political theory; therefore, in both sections of the course, we encouraged students to craft their contributions so as to expand understanding of the topic in question, clarify key concepts, push discussions in new directions, offer insight on course readings, and promote civility and a collegial atmosphere. In both venues, we modeled the type of interaction that we expected from students. Although we should expect both motivated and unmotivated participants in each venue, discussion takes quite different forms. There is now a growing body of scholarship suggesting that asynchronous online discussions offer greater benefits for developing critical-thinking skills because students have more time to reflect on the material, ask more complicated questions, and address one another in addition to the instructor (Schumm et al. 2006; Szabo and Schwartz 2011). Instructors must watch for "recycled" and redundant posts; however, for motivated

\section{Too often, online courses are envisioned as mere reproductions of on-campus courses rather than opportunities that demand careful attention to the dynamic relationship between creating a learning environment and fostering specific student capacities. Unfortunately, this is a trap into which we fell.}

nontraditional students-will not have access to the content or practices of the subfield. Much of the work that political theorists do in the classroom-primarily through student participation and writing assignments-is directed toward cultivating critical-thinking skills, interpretive ability, argumentation, and political judgment. Also, whereas there is much to suggest that online courses allow for the development of both student discussion and individual writing skills, there has been little (if any) work dedicated to teaching political theory online. The primary focus of comparative pedagogical research in online and on-campus teaching has been empirical studies of student engagement and success in meeting learning outcomes (Anstine and Skidmore 2005; Botsch and Botsch 2012; Dolan 2008). In contrast, we seek to identify specific challenges of teaching critical thinking online.

Too often, online courses are envisioned as mere reproductions of on-campus courses rather than opportunities that demand careful attention to the dynamic relationship between creating a learning environment and fostering specific student capacities. Unfortunately, this is a trap into which we fell. In defining the two courses, our initial goal was to make them as similar as possible. Toward that objective, we constructed PowerPoint slide shows with lectures (oncampus) and voice-over audio (online) that were delivered in each venue. We began the on-campus and online discussions with the same questions and sought to replicate the character of dynamic students, the online discussion thread diminishes the intimidating aspects of public speaking and presents an opportunity for deeply reflective engagement. In contrast, on-campus discussions are more easily distracted, lethargic, or truncated due to the limited time, energy, and preparation of participants.

Given these limitations, on-campus discussion often is enhanced by creating incentives for reflection prior to class, such as requiring students to bring discussion questions to class or to submit a paragraph that identifies a key puzzle or concept central to the reading. Often, these discussions also benefit from exercises that energize the classroom and provide greater opportunity for student exchange, such as jigsaw exercises or movement from small- to large-group discussions. In contrast, although instructors must work to keep online discussions focused and moving, our experience suggests that limiting the number of threads and simplifying the process for engaging in discussion are critical to success. For example, in our BCA exercise, we attempted to mirror the on-campus experience by creating multiple online threads for sequential small- and largegroup discussions. The result was decreased participation because the process was too complicated. Thus, what was easy and productive on-campus was cumbersome and ineffective online.

We cannot compare the improvement in critical thinking through participation across venues; however, students' evaluations suggest that the discussions were essential to their comprehension of 
the material. Given our experience, we remain convinced that student discussion is critical to maintaining engagement and improving critical-thinking skills whether they occur online or on-campus. However, we note that maintaining the same level of interaction requires significantly more instructor time in the online format. In the future, we will optimize this time by heightening the expectations for participation by adding specific writing requirements and increasing the online course weighting of this element.

In addition to building critical-thinking skills through student participation, we assigned a multistep final research paper that required students to apply theories of justice to a specific conflict in which claims of environmental injustice were voiced; to gather, sift, and interpret data related to an environmental-justice issue; and to use specific concepts introduced in the course to analyze the chosen case. We divided the environmental-justice case study into three separate documents (graded satisfactory/unsatisfactory) that culminated in a final draft (traditional letter grading) to manage the expectations and to encourage students to rethink, revise, and edit. Students received significant instructor feedback on each assignment, thereby allowing intervention and course correction when necessary. The process also included peer review and oral presentations of the final research paper. As Çavdar and Doe explained, structuring the writing process as a series of steps, each with instructor feedback, "provides not only a unique opportunity for students to hone their critical thinking skills but also provides students with incentive to pay attention to an instructor's feedback" $(2012,298)$. As research on the problems attending "high stakes" writing assignments suggests (see, e.g., Elbow 1997), breaking up the paper into steps and providing the opportunity for revisions increased the potential for improvement in both the form and the content of the students' arguments. The process also required them to begin their research early in the semester and to make continued progress on the paper as the course proceeded.

Overall, the final research papers were impressive. However, the online format presented particular challenges in the presentation of the assignment, the practice of peer review, and the sharing of knowledge through oral presentation. Although asynchronous discussion offers advantages for reflective exchange, we found that it was not sufficient to post the assignment and offer space for questions in the discussion threads. In the future, the posted assignment will be accompanied by an online lecture, a "frequently asked questions" document, specific examples, and exercises designed to clarify the assignment expectations. Future iterations of the course also will standardize online peer review through the repeated use of an online document-sharing program (e.g., Google Drive) that would allow not only the instructor but also students to review one another's work. Finally, in future iterations, we hope to take advantage of either PowerPoint voice-over technology or personal movie-producing technology to make the oral-presentation component of the final paper assignment a more engaging activity for online students. Without these technologies, the presentation of students' work does not do justice to either their investment in the material or their effort on the project.

\section{CONCLUSION}

Ultimately, our experiment in teaching environmental justice through political theory on-campus and online produced a sea of riches. Courses like this one have the potential to expand the reach of political theory, to diversify the traditional theory classroom, to create opportunities for interdisciplinary education and communication, and to contribute necessary substantive knowledge to students who are likely to participate in decision making across the environmental policy and management fields. Moving forward, we recognize that teaching political theory online requires a creative approach, particularly in producing the synergistic effects of collective learning that emerge in on-campus courses. Nevertheless, we are committed to making rigorous, interesting, and relevant courses available to the entire range of students who desire to learn. Thus, we encourage work directed toward developing effective models and modules for teaching political theory both oncampus and online.

\section{NOTES}

1. For readability, the use of "we" is adopted throughout the article; however, both authors were not involved in all aspects of the course.

2. The structure of our course is similar to that described by Robert Figueroa (2002)

3. Each class was capped at 25 students.

4. In our effort to demonstrate to students both the lived experience and proximity of environmental-justice issues, we also included documentaries and a guest speaker from the Wind River Indian Reservation.

\section{R E F E R E N C E S}

Anstine, Jeff, and Mark Skidmore. 2005. "A Small Sample Study of Traditional and Online Courses with Sample Selection Adjustment." Journal of Economic Education 36 (2): 107-27.

Auerback, Arthur H. 2012. "Teaching Diversity: A Multifaceted Approach to Engage Students." PS: Political Science and Politics 45 (3): 516-20.

Botsch, Carol S., and Robert E. Botsch. 2012. "Audiences and Outcomes in Online and Traditional American Government Classes Revisited." PS: Political Science and Politics 45 (3): 493-500.

Çavdar, Gamze, and Sue Doe. 2012. "Learning through Writing: Teaching Critical Thinking Skills in Writing Assignments." PS: Political Science and Politics 45 (2): 298-306.

Di Chiro, Giovanna. 2006. "Teaching Urban Ecology: Environmental Studies and the Pedagogy of Intersectionality." Feminist Teacher 16 (2): 98-109.

Dillon, Patrick. 2006. "Creativity, Integrativism and a Pedagogy of Connection." Thinking Skills and Creativitiy 1: 69-83. ]

Dillon, Patrick. 2008. "Pedagogy of Connection and Boundary Crossings: Method ological and Epistemological Transactions in Working Across and Between Disciplines." Innovations in Education and Teaching International 45 (3): 255-62.

Dolan, Kathleen. 2008. "Comparing Modes of Instruction: The Relative Efficacy of On-Line and In-Person Teaching for Student Learning." PS: Political Science and Politics 41 (2): 387-91

Elbow, Peter. 1997. "High Stakes and Low Stakes in Assigning and Responding to Writing." In Writing to Learn: Strategies for Assigning and Responding to Writing across the Disciplines, ed. Mary Dean Sorcinelli and Peter Elbow, 5-13. San Francisco: Jossey-Bass.

Figueroa, Robert. 2002. "Teaching for Transformation: Lessons from Environmenta Justice." In The Environmental Justice Reader: Politics, Poetics, and Pedagogy, ed. Joni Adamson, Mei Mei Evans, and Rachel Stein, 311-30. Tucson: University of Arizona Press.

Latuca, Lisa R., et al. 2004. "Does Interdisciplinarity Promote Learning? Theoretical Support and Researchable Questions." Review of Higher Education 28 (1): 23-48.

Schlosberg, David. 2013. "Theorizing Environmental Justice: The Expanding Sphere of a Discourse." Environmental Politics 22 (1): 37-55.

Schumm, W. R., F. J. Webb, D. E. Turek, K. D. Jones, and G. E. Ballard. 2006. "A Comparison of Methods for Teaching Critical Thinking Skills for US Army Officers." The American Journal of Distance Education 20 (1): 39-50.

Szabo, Zsuzsanna, and Jonathan Schwartz. 2011. "Learning Methods for Teacher Education: The Use of Online Discussions to Improve Critical Thinking." Tech nology, Pedagogy and Education 20 (1): 79-94.

Sze, Julie. 2006. "Bodies, Pollution, and Environmental Justice." Feminist Teacher 16 (2): 124-32. 